\title{
EL AJUAR FUNERARIO DEL ARZOBISPO DE ZARAGOZA Y VALENCIA, DON ALONSO DE ARAGÓN (1470-1520)*
}

\author{
Carolina Naya Franco ${ }^{1}$ \\ Universidad de Zaragoza
}

\begin{abstract}
El ajuar funerario del arzobispo y mecenas don Alonso de Aragón (1470-1520), hijo natural de Fernando el Católico, nos permite reflexionar sobre las inquietudes e intereses del prelado. Sus alhajas, encontradas en 1994 durante los trabajos de restauración de la Catedral del Salvador, por un lado materializan la internacionalidad de las relaciones del arzobispo, y por otro, las conexiones artísticas del Reino de Aragón en las postrimerías de la Edad Media.
\end{abstract}

Palabras clave: Ajuar funerario; Alonso de Aragón; báculo; discos; cruz pectoral.

\section{THE FUNERARY TREASURE OF THE ARCHBISHOP OF ZARAGOZA AND VALENCIA, DON ALONSO DE ARAGÓN (1470-1520)}

The funerary objects of the archbishop and patron of the arts Alonso de Aragon (1470-1520), illegitimate son of Fernando el Católico, allow for the consideration of this prelate's concerns and interests. His treasures, discovered in 1994 during the restoration of the Catedral del Salvador, on the one hand demonstrate the international nature of the archbishop's relations, and on the other, confirm the artistic connections of the Kingdom of Aragon in the late Middle Ages.

Key words: Funerary objects; Alonso de Aragon; crozier; circular badges; chest cross.

Cómo citar este artículo / Citation: Naya Franco, Carolina (2017): "El ajuar funerario del arzobispo de Zaragoza y Valencia, don Alonso de Aragón (1470-1520)". En: Archivo Español de Arte, vol. 90, núm. 360, Madrid, pp. 335-346. doi: 10.3989/aearte.2017.22

El arzobispo Alonso de Aragón, hijo natural del rey Fernando el Católico, fue un humanista y reconocido mecenas en el Reino de Aragón, en el tránsito a la Edad Moderna. Gran protector de las artes, comenzó un ambicioso plan arquitectónico para transformar la primitiva catedral gótica del Salvador, en una esbelta planta de salón². Y aunque su proyecto inicial tuvo que replantearse en 1498 y no pudo verlo concluido, sufragó la finalización del retablo mayor de la Seo a cargo del escultor Gil Morlanes (1484-1487), así como el comienzo de su cimborrio, además de contribuir con distintas rentas y capellanías al mecenazgo y promoción de pintores, músicos y poetas asiduos a su residencia episcopal.

* El presente artículo se enmarca entre las iniciativas del grupo de investigación consolidado: "Artífice" (248129/1), cofinanciado entre el Gobierno de Aragón y el Fondo Social Europeo y dirigido por la catedrática de historia del arte, doña Carmen Morte García.

1 naya@unizar.es / ORCID iD: http://orcid.org/0000-0002-0649-8124.

2 Sobre Alonso de Aragón como mecenas de las artes: Morte García, 1998:175-247; Morte García, 2000: espec. 147155; Ibáñez Fernández, 2000: espec. 293-297; Criado Mainar / Ibáñez Fernández, 2007:1421-1444. 


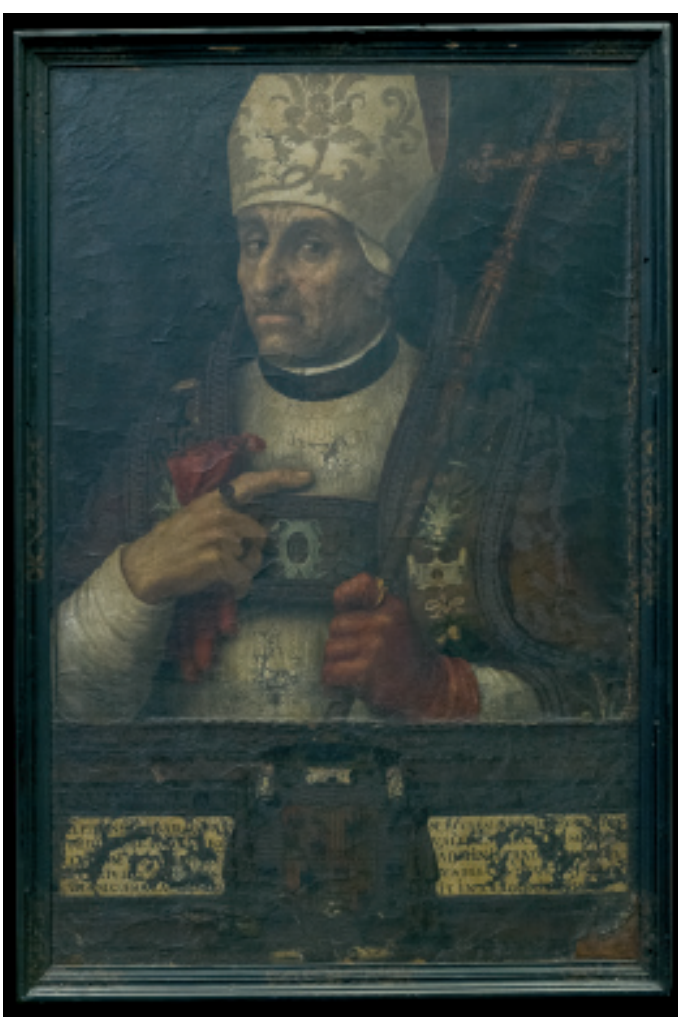

Fig. 1. Retrato del arzobispo don Alonso de Aragón, atribuido al taller de Juan de Juanes (1568).

Óleo sobre cuero, $83 \times 56 \mathrm{~cm}$. Fotografía de Juan Monzón Gasca, cortesía del cabildo de la catedral de Valencia.

Hombre de armas y de letras a la manera de los prohombres renacentistas, además de publicar distintos escritos relacionados con sus cargos religiosos, también fue un gran estratega militar y bastión político de su padre Fernando II de Aragón, demostrando -a pesar de su juventud-, gran control en distintas vicisitudes producidas durante las ausencias del rey ${ }^{3}$. No obstante, la principal labor del prelado fue ostentar el cargo de arzobispo de Zaragoza durante más de cuarenta años (1478-1520), además de los arzobispados de Valencia (15121520) y Monreale (Sicilia) y de ocupar distintos cargos eclesiásticos, honoríficos y políticos, como los de abad de Rueda, San Victorián o Montearagón, archimandrita de Sicilia, patriarca de Jerusalén o canciller y virrey de Aragón. A este respecto, reproducimos un retrato del arzobispo en la sacristía de la catedral de Valencia por tratarse de una obra poco conocida (fig. 1), frente al ejemplar barroco de cuerpo entero que forma parte de la galería de retratos de la sede cesaraugustana, repartida entre las salas inmediatas y el Salón del Trono en el Palacio Arzobispal ${ }^{4}$. El arzobispo se representó entonces con varios anillos pastorales que muestran la moda renaciente.

En las próximas páginas nos centraremos en el estudio del ajuar funerario que se encontró en el interior del enterramiento del arzobispo en 1994, durante las obras de restauración de la zaragozana catedral del Salvador. A partir del análisis de las alhajas que debieron conformar su ajuar, podemos reflexionar no solo sobre cómo el prelado fue enterrado en el presbiterio de la catedral delante del altar y del retablo mayor rodeado de las armas que legitimaban su estirpe real, sino que además podemos constatar la internacionalidad de las relaciones del arzobispo, así como materializar sus principales inquietudes e intereses. Tanto su báculo, símbolo de autoridad eclesiástica, como los discos esmaltados y su cruz relicario, son exponentes del cosmopolitismo y conexiones artísticas del Reino de Aragón a través de sus manifestaciones plásticas, ya en la Baja Edad Media.

No obstante y antes de ocuparnos de las alhajas en detalle, a partir de la revisión de los expedientes de estas piezas conservados en el Servicio de Conservación y Restauración de la Diputación General de Aragón, cabe citar dos premisas,: la primera, que según el informe publicado por el equipo de arqueólogos que trabajó en las excavaciones de la Seo zaragozana ${ }^{5}$, las piezas de las que vamos a ocuparnos se encontraron en el interior del enterramiento que custodia los restos de don Alonso, situado entre la primera y la segunda fosa del presbiterio; y la segunda, que a los pies de don Alonso se encontraron unos segundos restos óseos, sobre cuya naturaleza

\footnotetext{
${ }^{3}$ Hijo de una dama de la nobleza catalana, el Rey Católico le confió varios puestos políticos, porque le tenía gran afecto y confianza. Como recuerda en ocasiones la profesora Carmen Morte, fue el único de los hijos naturales al que citó en su testamento.

${ }^{4}$ Sobre la galería de retratos aragoneses: Ansón Navarro, 1991:145-148. Lozano López, 2001-2003: espec.312-315.

${ }^{5}$ Hernández Vera / Bienes Calvo / Casasús Alcaine, 1997: 429-430.
} 
e identificación, se presentaron opiniones dispares, plasmadas en distintos informes el año de las excavaciones.

También cabe aclarar que el estilo histórico-artístico de tres de las joyas encontradas hoy localizadas, tal y como anunció Arbeteta cuando se descubrieron las piezas, no coincide en ningún caso con la fecha de óbito del arzobispo, sino que se trata en todos los casos de alhajas anteriores: el pectoral, en forma de cruz de Jerusalén es una pieza románica (Siglo XI) ${ }^{6}$ y los discos esmaltados y báculo, son ejemplares góticos (Siglo XIV). De este modo, aunque los informes

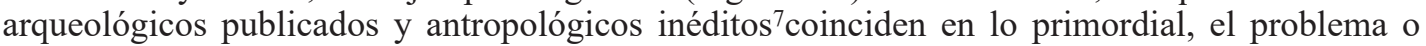
disparidad surge en la identificación o naturaleza de los segundos restos óseos replegados y amontonados a los pies de don Alonso, también ubicados por lo tanto en el interior de la fosa. Revisaremos sucintamente esta cuestión, a partir de ambos planteamientos.

La primera hipótesis publicada por José Antonio Hernández Vera al frente del equipo de arqueólogos, es que los segundos restos óseos encontrados podrían pertenecer al que fue abad de Montearagón y arzobispo de Zaragoza, don Pedro López de Luna (1317-1345). Su cuerpo habría sido colocado provisionalmente en una fosa del presbiterio, al no haberse finalizado a su fallecimiento la capilla de San Bartolomé (actual capilla de Santiago), donde previsiblemente debía haber sido enterrado. En este sentido, el prestigio del lugar elegido para el enterramiento temporal y el hecho de que a la muerte de don Alonso estos restos no fueran retirados, corroborarían para los arqueólogos la identificación del personaje. Esta teoría se sustenta en las memorias eclesiásticas de la ciudad, manuscritas por Diego de Espés (†1602): el que fue beneficiado y racionero de San Salvador dejó constancia de cómo los restos del arzobispo Pedro López de Luna se depositaron -mientras su capilla se terminaba- delante del altar mayor: "coram altari maiori"8. En cualquier caso, a día de hoy no cabe la menor duda para el equipo de arqueólogos dirigidos por el emérito profesor Hernández Vera, que las tres alhajas de las que nos ocupamos aquí (cruz pectoral, discos esmaltados y báculo) formaron parte del ajuar funerario de don Alonso.

El segundo planteamiento, propuesto por el antropólogo y doctor en ciencias José Ignacio Lorenzo Lizalde en su informe sobre las excavaciones de 1994, refería que los segundos restos podrían haber pertenecido al primer arzobispo de Zaragoza tras la liberación de la ciudad del dominio musulmán, don Pedro Librana, activo todavía en $1129^{9}$. De este modo, por lo sobrevenido de la muerte de don Alonso al cual se habría enterrado apresuradamente (sin anillo pastoral, descalzo y en el mismo lugar que a una dignidad anterior), se dejó al antiguo prelado a los pies del hijo de Fernando II de Aragón. El antropólogo nada refirió acerca de la cruz pectoral, que por cronología y estilo coincidiría plenamente con el acaecimiento de Pedro de Librana ${ }^{10}$.

Por lo demás, ambos informes concuerdan en explicar cómo el arzobispo, amortajado con el traje pontifical aderezado con dos discos esmaltados, sostenía el báculo entre ambas manos, cubiertas con guantes o quirotecas verdes. A este respecto, remitimos a la (fig. 2). El báculo, al abrir la fosa, cruzaba en diagonal el cuerpo del prelado, preservado sobre un encomiástico y

${ }^{6}$ La joya ha sido fondo de varias exhibiciones temporales: Arbeteta Mira, 1995: 188-195; Torra de Arana, 2000 : 444; Naya Franco, 2015:192-193.

${ }^{7}$ Lorenzo Lizalde, Informe antropológico sobre don Alonso de Aragón, arzobispo de Zaragoza, inédito y sin fecha, conservado en el interior del expediente del enterramiento de don Alonso, en el Servicio de Conservación y Restauración del Patrimonio Cultural de la Dirección General de Cultura y Patrimonio del Gobierno de Aragón (expedientes 46/98, signaturas 3796; 47/98, signaturas 3797 /29172; 20/97, signaturas 3794/29164). Agradecemos las atenciones del asesor técnico del Gobierno de Aragón, Carlos Oliván Villobas; las de la archivera de la administración del Gobierno de Aragón, María Isabel Rojas Serrano y las gestiones de la Jefa de sección de Bienes Muebles del Patrimonio Cultural, Iciar Alcalá Prats.

${ }^{8}$ Espés, Historia ecclesiastica de la ciudad de Çaragoça desde la venida de Iesu Christo Señor y Redemptor nuestro hasta el año de 1575, 2 tomos, Ms. Biblioteca Capitular de Zaragoza, sig. 20-47 y 20-48, libro IV, f.545.

9 Se creyó acaecido ya en 1128: Ubieto Arteta, 1957: 60.

${ }_{10}$ En su informe, el técnico ya apuntó que tenía los permisos pertinentes y muestras para analizar los segundos restos. Sin embargo, nos confirmó hace unos meses que el ADN no resultaba operativo al no tener familiares con los que comparar. Quedaría pendiente una prueba de carbono 14 para identificar al segundo prelado, que todavía no se han llevado a cabo al no contar con financiación específica. 


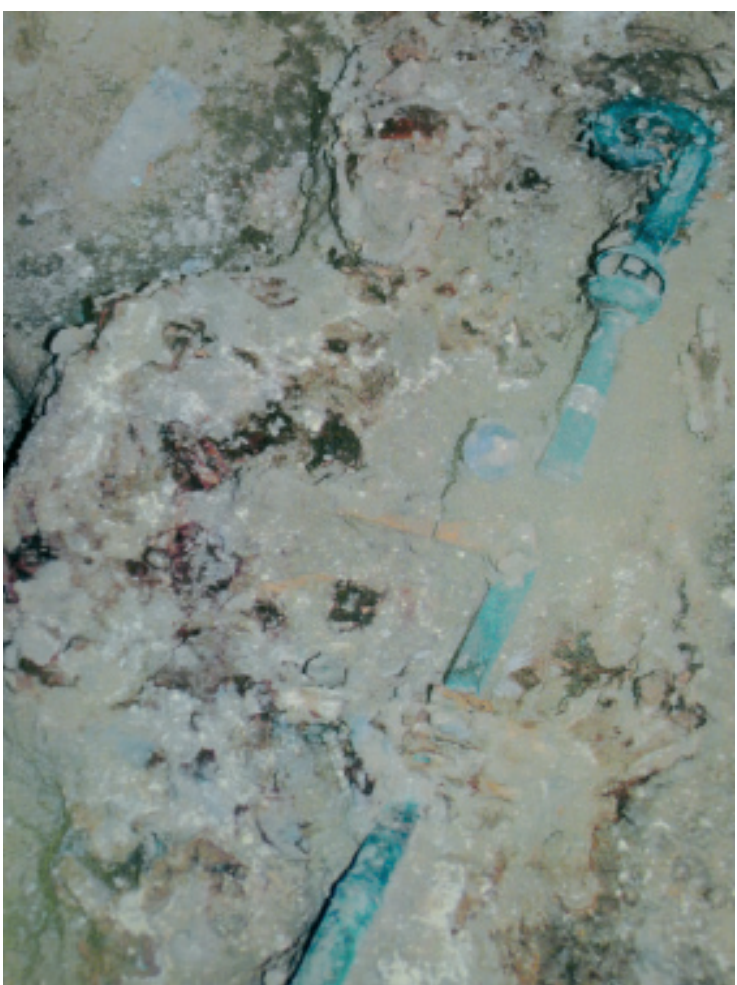

Fig. 2. Detalle de los restos de don Alonso de Aragón en la apertura de su enterramiento en 1994, situado en el presbiterio de la Catedral del Salvador. Imagen reproducida en el informe de Lorenzo Lizalde, cortesía del Servicio de Conservación y Restauración de la Diputación General de Aragón. aromático fondo de hojas de laurel. Sobre la legitimidad de los discos y báculo como propiedad del mecenas, no existe por lo tanto la menor disparidad.

De cualquier modo, aunque la cronología del pectoral es muy anterior a don Alonso, podemos dar por sentado que las tres alhajas pudieron ser escogidas de entre las pertenencias del hijo natural del rey católico para acompañar sus restos, porque eran piezas que solía portar y que debían tener para él gran valor artístico y simbólico. Todas las piezas serían joyas heredadas, u ofrendas derivadas de sus variadísimas prebendas que materializarían las principales inquietudes e intereses del arzobispo Alonso de Aragón ${ }^{11}$. Por otro lado, además de las tres joyas actualmente localizadas en las que centraremos nuestra intervención ${ }^{12}$, se encontraron en el mismo enterramiento -según el extenso informe arqueológico-, otras piezas que al desconocer su paradero actual no han sido objeto de nuestro estudio, como una hebilla de bronce y dos placas de plomo de una estola.

Contextualizadas las joyas encontradas en el enterramiento, comenzaremos por analizar el precioso pectoral relicario en forma de cruz de Jerusalén cuya altura revela la pieza como una obra arquitectónica de reducidas dimensiones: el fondo de la alhaja que sirve de armazón a los dos registros de planchas recortadas que configuran el diseño es una arquería de medio punto y a modo de los claustros románicos, presenta una prefiguración del paraíso en forma de dos pisos de grafilillas y cordoncillos (fig. 3) ${ }^{13}$. Esta manufactura incardina esta joya con otras obras de carácter internacional.

En el territorio hispánico, se conservan pocas alhajas con motivos decorativos y plásticos similares al pectoral encontrado en el enterramiento de don Alonso: a este respecto, además del cáliz leonés de doña Urraca que muestra una arquería de medio punto en el pie, es preciso señalar el parentesco del pectoral zaragozano con una pieza que se conserva en el Museo Diocesano de Astorga, ya que ambas se configuran de una forma muy similar en su fondo o altura. La joya

${ }^{11}$ La Diputación General de Aragón dio cuenta sucintamente de las intervenciones en las tres piezas de las que vamos a ocuparnos: Galindo Pérez, 2010: 895-896; 897-899; 902-903.

${ }^{12}$ El pectoral y los discos se encuentran expuestos en una pequeña vitrina, ubicada en la entrada de la Sala $\mathrm{n} .{ }^{\circ} 2$ del Museo de Tapices, en la primera planta de la Seo zaragozana. El báculo de don Alonso debe custodiarse en la sacristía del templo. A día de hoy, no nos ha sido posible examinar este ejemplar al natural.

${ }^{13}$ La alhaja, se restauró por Mercedes Blanco en 1998. Se intervino con una limpieza y consolidación básica: Blanco Ruano, Memoria de intervención en la cruz pectoral procedente del enterramiento de Don Alonso de Aragón, inédito, 1998, Servicio de Conservación y Restauración del Patrimonio Cultural de la Dirección General del de Cultura y Patrimonio del Gobierno de Aragón (expedientes 46/98, signaturas 3796; 47/98, signaturas 3797 /29172; 20/97, signaturas 3794/29164). 


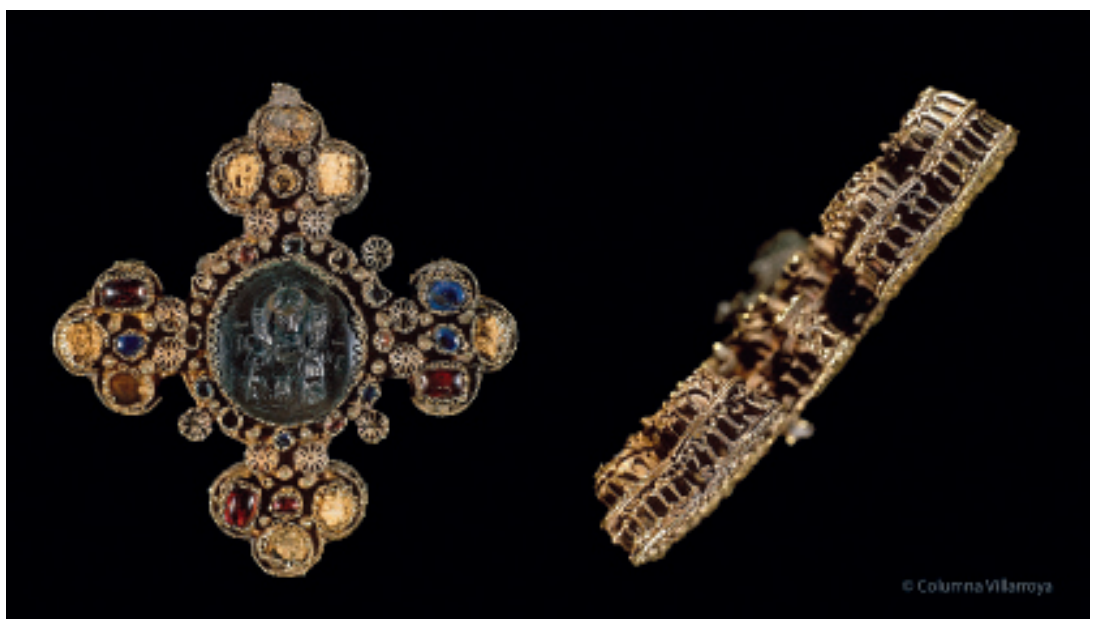

Fig. 3. Anverso de la Cruz pectoral encontrada en el interior del enterramiento de Alonso de Aragón y detalle del fondo. Ancho y alto: $7,48 \mathrm{~cm}$. Fondo: $0,9 \mathrm{~cm}$. Fotografía de Columna Villarroya ${ }^{\circledR}$. Imagen cortesía del cabildo metropolitano de Zaragoza.

astorgana fue emparentada con algunas joyas italianas, en un fantástico y detallado estudio del profesor Jorge Aragoneses ${ }^{14}$.

El conocido como broche de Astorga (Siglo XI), hoy en el museo catedralicio, presenta cuatro esmaltes tabicados bizantinos con la figuración de los evangelistas, y su representación central, hoy perdida, se engastó con una labor de hilo similar a la zaragozana, denominada por Jorge Aragoneses como labor de bucles o de "oro rizado". Ya hemos señalado en otras ocasiones la dificultad de establecer hipótesis o adscripciones geográficas determinadas para las alhajas, fundamentalmente debido a la ausencia de marcas en las joyas de toda Europa prácticamente hasta Época Contemporánea; no obstante, el profesor murciano señaló la posibilidad de que la alhaja astorgana fuera una obra milanesa, aunque tampoco descartó que tuviera un origen noroeste peninsular hispánico, hacia el cual nos inclinamos. No obstante, el estudio de la pieza leonesa, muy anterior al descubrimiento de la alhaja zaragozana, permite establecer analogías entre la manufactura de ambas joyas, así como otros paralelismos con obras de orfebres del ámbito europeo y mediterráneo.

El reverso del pectoral de la Seo ${ }^{15}$ presenta un registro calado y seriado de virtuosa labor de filigrana de hilo entorchado configurada por medio de volutas de cordoncillos sogueados similar a piezas internacionales tempranas, como los que se recrean en algunos detalles del casquete y túnica de la efigie relicario de St Foy de Conques ${ }^{16}$. Pero la cruz relicario también se puede emparentar con alhajas alfombradas de filigrana avanzado el siglo XVI, como un ejemplar del Walters Art Museum (57-1511a-c). Ambas alhajas son herederas de la tradición bizantina: la joya americana, al igual que la zaragozana, también reutiliza una gema tallada en época bizantina; en este caso un camafeo de la Virgen y el Niño decorado en su perímetro con casquillas similares a las del pectoral de don Alonso, y que acogen en la pieza americana perlas remachadas ${ }^{17}$.

Por otro lado, el joyel custodiado en la catedral zaragozana ha perdido con la desaparición de sus gemas, gran parte de su suntuosidad originaria heredada de la tradición bizantina: cuarenta piedras preciosas adornaron el pectoral en época prerrománica, cuando -tal y como rememora la

14 Jorge Aragoneses, 1960-1961: 31-43. El artículo incluye el fondo y varias vistas de la pieza leonesa y está visible en la web de Digitum, el depósito institucional de la Universidad de Murcia: https://digitum.um.es/xmlui/bitstream/10201/21742/1/03\%20El\%20broche\%20romanico\%20de\%20Santo\%20Toribio\%20de\%20Liebana \%20y \%20 su\%20probable\%20origen\%20milanes.pdf La catalogación de Jorge Aragoneses, obviamente continúa utilizándose: Encrucijadas. Las edades del hombre, Catedral de Astorga, cat.exp. 2000: 280-281.

15 El reverso de la alhaja zaragozana puede visionarse online, en el Archivo Fotográfico del Gobierno de Aragón: http://www.patrimonioculturaldearagon.es/bienes-culturales/relicario-pectoral-de-don-alonso-de-aragon.

16 Robinson, 2011:34 y ss.

17 Un sucinto estudio de la pieza americana se realizó por Sabine de Albersmeier: Albersmeier, 2005: 36-37. 


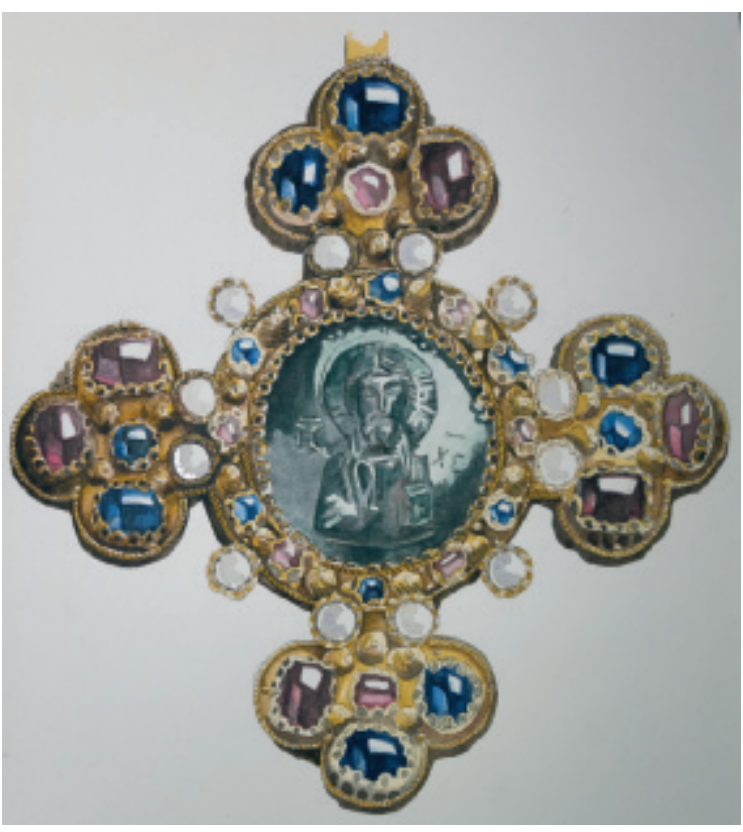

Fig. 4. Boceto en acuarela que recrea la apariencia original del pectoral encontrado en el enterramiento de don Alonso de Aragón, con las cuarenta gemas que originalmente guarnecían su estructura. Autor: Juan Monzón Gasca (2016). historiografía clásica de la joyería artística-, Bizancio debía erigirse como "el París de la Edad Media"18. En este sentido, cabe reproducir un boceto que recrea la apariencia original que debió tener la alhaja, a juzgar por los restos de pernios que todavía presentan los alveolos en su interior y las gemas conservadas: una estructura tapizada de gemas de distinta transparencia, color y calidad de matices (fig. 4). En la recreación figuran todas las perlas que ostentaba (doce en total), e incluso el último de sus cuatro alveolos (hoy perdido), que a modo de casquillas dispuestas entre los intersticios presentaba entre sus brazos trilobulados. Cada uno de estos cuatro alveolos, acogía una perla. Del mismo modo, asidas al fondo de las casquillas por medio de pernios, en la base de los brazos otros ocho alveolos protegían anacaradas perlas en forma de "asientos", o "llanas de un lado" en términos de Juan de Villafañe $(1572)^{19}$.

En cuanto al resto de gemas originarias, únicamente perduran en la actualidad ocho cabujones redondos entre los pequeños pináculos entorchados alrededor del camafeo central; en concreto, zafiros azules de poca transparencia combinados con cristalinos granates piropo que todavía se engastan en forma de "bucles". En los brazos trilobulados, también figuran algunos cabujones de zafiros y granates de distintos contornos redondeados. De cualquier modo resulta cuando menos inquietante la desaparición de todas estas gemas, de naturaleza inorgánica, que deberían haberse conservado intactas en el interior de la fosa. Quizás se hurtaron gemas de la alhaja cuando el suelo de la catedral fue removido en el siglo XVIII. En cualquier caso, cabe señalar que al igual que en la joya astorgana, las gemas se colocaron sobre lechos de cera virgen, que hoy se presentan como restos petrificados. Este material dispuesto en el fondo de la estructura, permitía utilizar piedras preciosas de menor tamaño y en cualquier caso que las gemas resaltaran en el diseño, al alcanzar la altura deseada.

De cualquier modo, el pectoral relicario zaragozano presenta en el centro de la composición, su representación central original: un camafeo bizantino de contorno circular de jaspe sanguino o heliotropo de $2,5 \mathrm{~cm}$., con un Pantocrátor altomedieval tallado en alto y medio relieve. Este camafeo se reutilizó, -al igual que en otras obras prerrománicas hispánicas-, para guarnecer el pectoral de una montura románica del siglo XI. En esta época la joya debía ser una cruz pectoral pinjante, ya que hoy presenta restos de una primitiva reasa que sirvió para colgar la cruz de un cordón o cadena.

Posteriormente la cruz se debió llevar prendida a modo de fíbula, quizás como remate de la capa. Multitud de representaciones plásticas de tiempos de don Alonso nos permitirían corroborar cómo pudo portar la joya en el centro del pecho, entre los dos discos góticos del

18 Wagner de Kertesz, 1947: 258.

19 De Arfe y Villafañe, 1572: f.62v. 


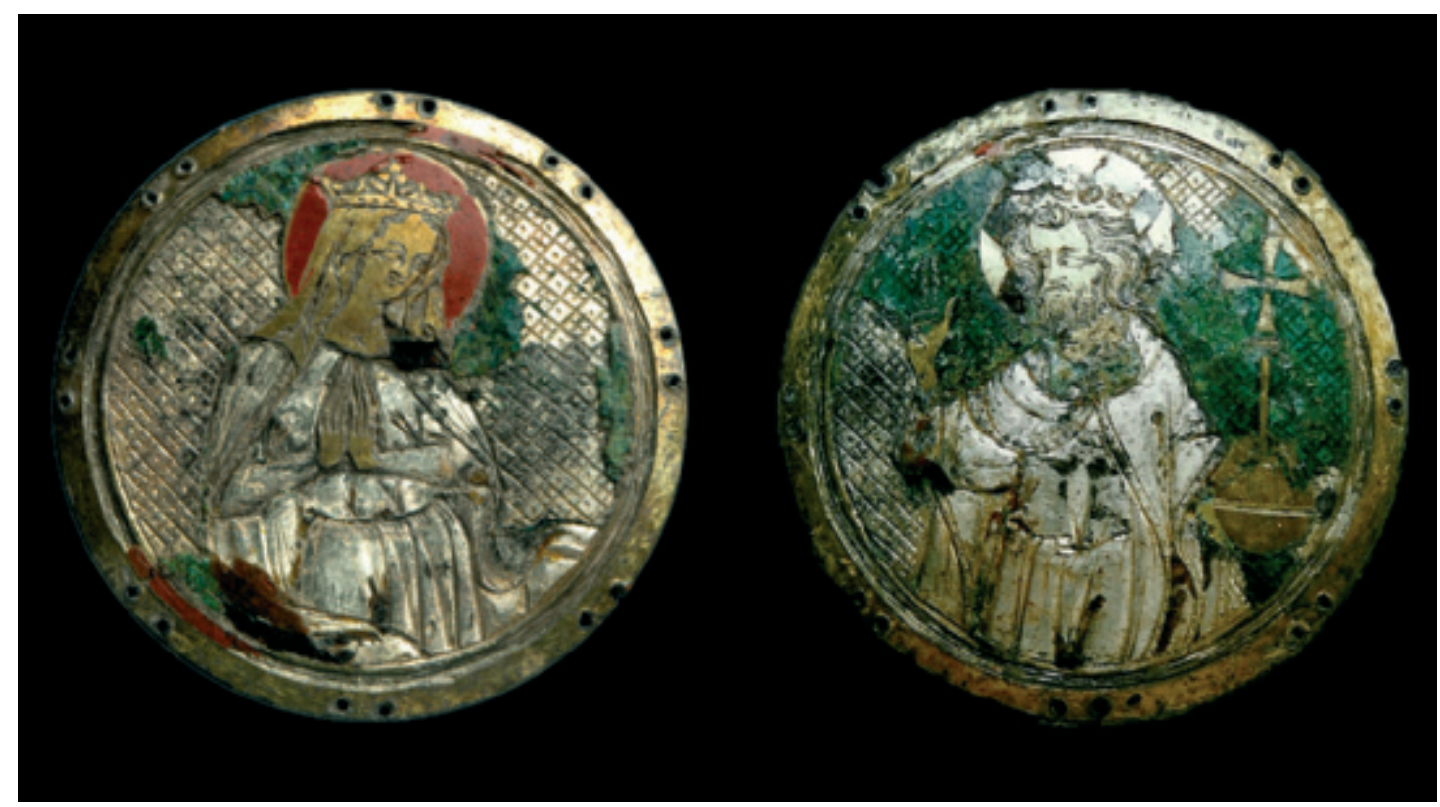

Fig. 5. Discos esmaltados góticos de don Alonso de Aragón. Diámetro: 4,6 cm. Fotografía de la autora, con retoques digitales de Inmaculada Fañanás. Imagen cortesía del cabildo metropolitano de Zaragoza.

Salvador y la Virgen. A este respecto cabe citar entre otros, el joyel que porta el ángel que presencia el Bautismo de Cristo del flamenco Juan de Flandes, en la colección Abelló (ca. 14961499); el del papa Liberio en el Milagro de la Nieve por Bartolomé Bermejo y Martín Bernat (1479-1484); el de San Victorian entre San Gaudioso y San Nazario hoy en la catedral de Barbastro (1485-1495), o incluso el propio broche de Astorga, que fue sujeción de la capa pluvial de la talla en madera de Santo Toribio de Liébana, posiblemente desde su concepción por parte de Gaspar de Becerra (1558-1562) y quizás por expreso deseo del comitente de la escultura $^{20}$.

La denominación de la alhaja como "encolpión" (según la acepción griega del término "en el pecho") responde a los valores simbólicos y tipológicos de la joya: presenta forma de cruz presidida por un icono central y contiene una reliquia en su interior. En este caso, la interesante alhaja zaragozana presenta un fragmento de lignum crucis entre tela adamascada y se protegía por medio de una tapa de oro o plata sobredorada en forma de cruz griega, que hoy no se conserva. La gema que configura el camafeo central, en jaspe sanguino o heliotropo, se denominó históricamente como "piedra de sangre". Las manchas rojizas sobre el verde opaco del camafeo, eran pequeñas alegorías que materializaban "gotas de la sangre de Cristo". La joya se configuró por lo tanto desde la Baja Edad Media como un "talismán" que tendría atribuidas cualidades protectoras.

En cuanto a los discos góticos a modo de tondos con representaciones del Salvador y la Virgen en oro y plata esmaltada (fig. 5), podemos denominarlos como estructuras "de apariencia"

${ }^{20}$ En 1954 la joya, asida a la talla por medio de tres clavos de forja, se desprendió de la madera cuando la escultura se llevó desde el banco del retablo mayor de la Catedral leonesa, hasta su nueva ubicación en el Museo Diocesano de Astorga. 


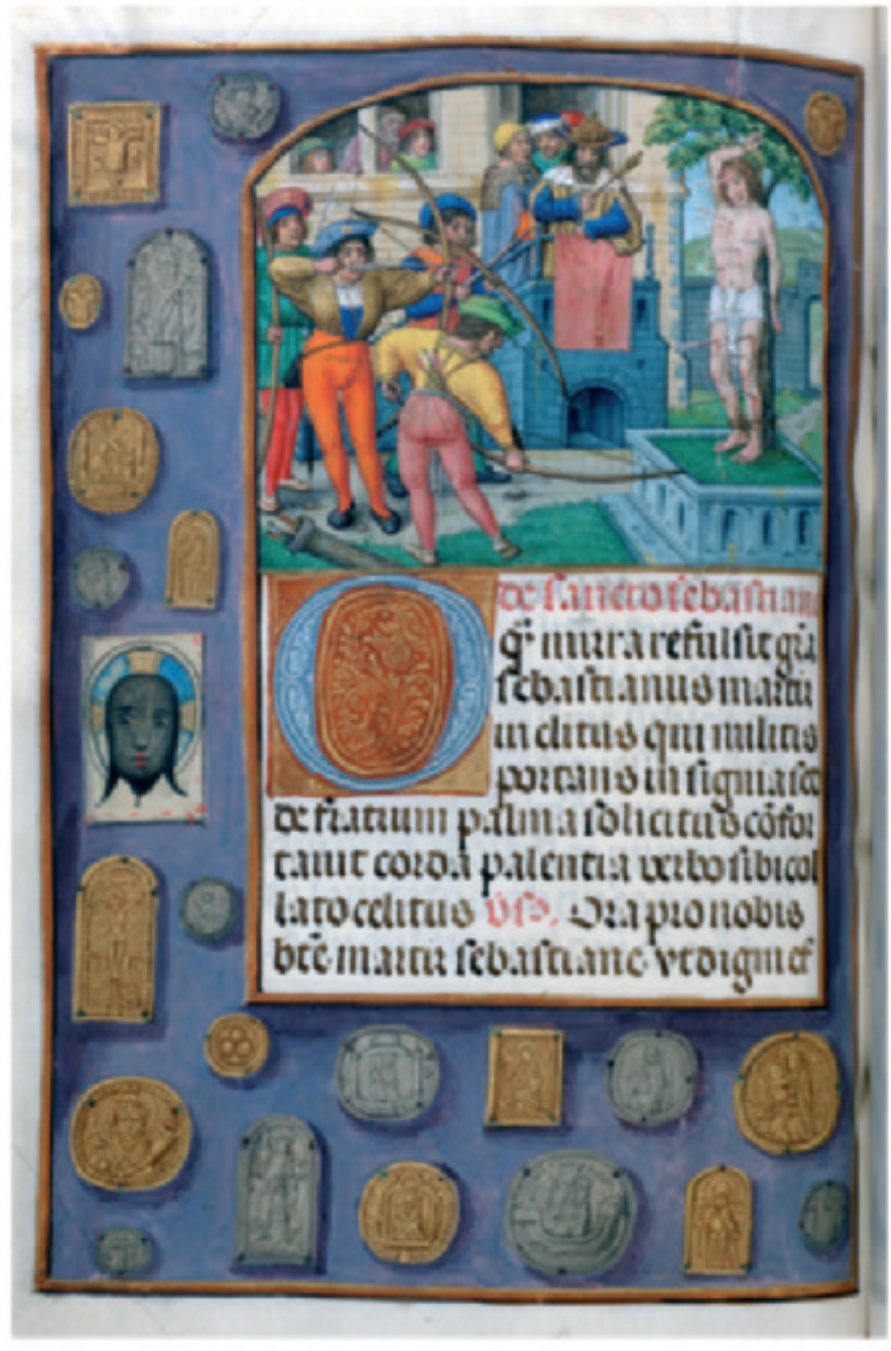

Fig. 6. Miniatura del Soane hours. Ms.4, Vol.137, f.112v. $(10,5 \times 7 \mathrm{~cm})$. Imagen cortesía del Sir John Soane's Museum.

ya que sin trabajar en su reverso, se portaron como aplicaciones decorativas de paños -sobre todo masculinos-, a modo de fabulosos remates a la altura del pecho en tabardos, capuces o capas ${ }^{21}$.

Las representaciones de la Virgen y Cristo se esmaltaron en colores translúcidos y opacos, reservándose para las carnaciones láminas de oro a modo de forros sobre el metal blanco ${ }^{22}$.

Como producción, parece necesario emparentar estos discos con los talleres de la escuela limosina, favorecida en el siglo XIV por los Papas de Aviñón y los reyes de Navarra. Limoges,

${ }^{21}$ Bernis, 1962: 80-81; Bernis, 1979: 68. La funcionalidad de las piezas queda clara por las ocho parejas de orificios equidistantes en cercos sobredorados que ambos ejemplares presentan: cuando se intervinieron en 1997, en que se llevó a cabo en ellos una limpieza mecánico-química y posterior consolidación, se encontraron restos de seda adheridos al metal junto a las oquedades, por el interior convexo: Blanco Ruano, Memoria de intervención en los esmaltes procedentes del enterramiento de Don Alonso de Aragón en el altar mayor de la Catedral de San Salvador, Zaragoza, inédito, 1997, Servicio de Conservación y Restauración del Patrimonio Cultural de la Dirección General de Cultura y Patrimonio del Gobierno de Aragón (expedientes 46/98, signaturas 3796; 47/98, signaturas 3797 /29172; 20/97, signaturas 3794/29164).

${ }^{22}$ Los discos han formado parte de los fondos de algunas exposiciones: Coordinación "Aragón, Reino y Corona" (C.A.R.C.), cat.exp.2000: 445, n. ${ }^{\circ}$ 271-272; Naya Franco, 2015: 194-195. 

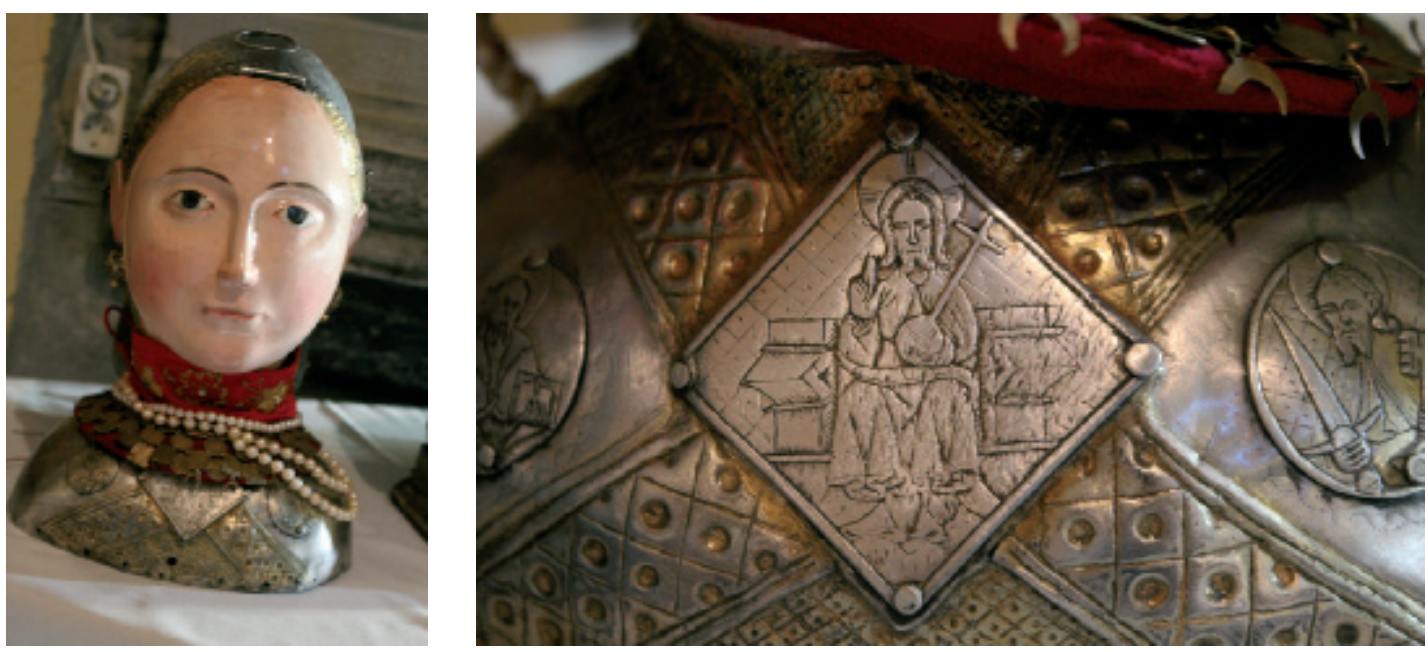

Figs. 7 y 8. Vista principal y detalle del busto en plata de Santa Orosia conservado en la Iglesia de San Lorenzo (Yebra de Basa). Fuente: fotografías de la autora, cortesía de la parroquia de Yebra de Basa (Huesca).

se benefició como punto estratégico de las ferias, del camino de Santiago y las peregrinaciones compostelanas ${ }^{23}$.

En cuanto a su temática, estas piezas solían presentar contenidos devocionales y se extendieron en variados contornos y distintos soportes, en las postrimerías de la Edad Media por toda Europa. Se cosían por sus pequeños orificios de modo individual a una de las mangas de prendas de camino a modo de "insignias de peregrinos", tal y como se pintó en el margen de la miniatura de un libro de horas flamenco conservado en el museo londinense de sir John Soane (Ms.4) (fig. 6), ya reproducido por Evans ${ }^{24}$. El librito ha sido catalogado en los últimos años, como posterior a $1512^{25}$.

No obstante la forma de portar estas parejas de discos se ve de nuevo reflejada en distintas manifestaciones plásticas; en este caso escultóricas, tal y como se representaron en el busto de plata de la mártir jacetana Santa Orosia conservado en la parroquia de San Lorenzo en Yebra de Basa (figs. 7 y 8 ).

La Santa patrona de toda la diócesis de Jaca porta una capa aderezada por discos gemelos aplicados a modo de tondos de San Pedro y San Pablo similares a los de don Alonso, flanqueando un Pantócrator central inscrito en un rombo. Las tres alhajas simuladas en el busto de Santa Orosia también debieron recibir decoración esmaltada ${ }^{26}$. El fondo de los discos esculpidos en el pecho de la mártir oscense muestra la misma estructura reticular incisa que los tondos del Salvador y la Virgen: una especie de "técnica preparatoria" que permitía fijar el esmalte, además de centrar el tema al presentar las figuras en primer plano sobre un fondo plano.

Recientemente, el profesor Criado ha catalogado esta parte del busto en plata de Santa Orosia como una obra de las postrimerías del siglo $\mathrm{XIV}^{27}$; una cronología con la que sin duda coincidimos, a partir de la tipología y estilo de alhajas que porta la Santa.

${ }^{23}$ Cabe señalar que en el reverso del disco del Salvador figura una inscripción incisa: XXX est ’7 Ø. Desconocemos si este elemento epigráfico podría adscribirse a un centro de producción concreto; quizás únicamente se refiera a un inventario de bienes antiguo de la Catedral del Salvador.

${ }^{24}$ Evans, 1970: 78-80 / plate 43.

${ }_{25}$ Morrison, 2003: 444 y ss. Se puede visionar en la Getty Publications Virtual Library: http://www.getty.edu/publications/virtuallibrary/0892367040.html.

26 Dedicamos al busto de Santa Orosia y sus aderezos un capítulo específico en Naya Franco, 2017: en prensa.

27 Criado Mainar, 2014: 344. 


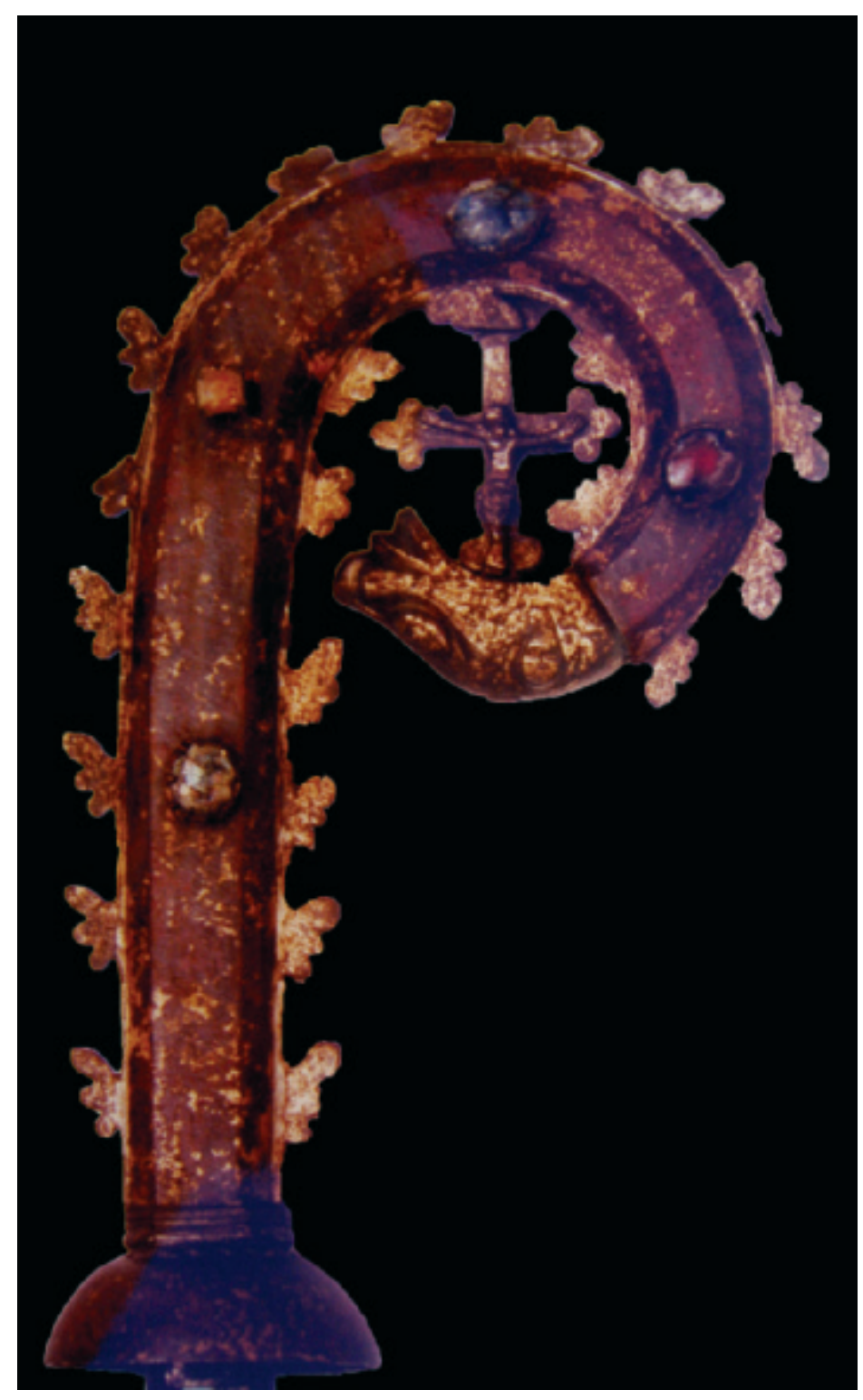

Fig. 9. Detalle del báculo de don Alonso. Fotografía Trácer, con retoques digitales Inmaculada Fañanás. Imagen cortesía del Cabildo Metropolitano de Zaragoza.

Ambos representados en los discos del ajuar de don Alonso, tanto Jesucristo como Salvator mundi (con orbe y cruz) como la Virgen, siguen los cánones del gótico internacional: se representan como bustos de formas muy esbeltas y alargadas, con nimbo circular (cruciforme en Jesucristo). La Virgen porta túnica con manto en ámbar de trasflor. Los aderezos para el cabello de ambos presentan coronas de tambor estrecho y crestería sencilla, a modo de las representaciones plásticas bajomedievales. Para algunos detalles del esmaltado, así como para la orla con rebajes a modo de pre-marco, se reservó el color rojo, todavía muy opaco.

Por último, en cuanto al báculo del ajuar funerario (fig. 9), en origen debió ser una caña de madera de un metro y cuarenta y seis centímetros de altura, forrada en bronce, compuesta por varias partes de sección circular ensambladas. En 2001 el báculo se reintegró sobre un alma de metacrilato. Su apoyadura, encorvada en forma de voluta, presenta forma cuadrangular y se recorrió por crestería vegetal, figurando en el centro una cruz trilobulada con el Salvador, que 
apoyaba a su vez por el extremo inferior en un terminal en forma de cabeza de perro ${ }^{28}$. La voluta parece decorarse además con aplicaciones de pastas vítreas engastadas en garras, que figuran efectos polícromos por medio de finas láminas de color adheridas a la base del material incoloro y cristalino.

En conclusión, y como ya adelantábamos en las primeras líneas del presente trabajo, las alhajas encontradas en el interior de la fosa que contiene los restos del arzobispo y mecenas Alonso de Aragón nos permiten reflexionar sobre las vastas conexiones artísticas del Reino de Aragón ya durante la Baja Edad Media.

También podemos ahondar en el modo de proceder en las ceremonias de inhumación de los arzobispos de la sede cesaraugustana y comprender parte de las inquietudes e intereses de nuestros prelados, a partir del estudio y la revisión exhaustiva de toda la documentación relativa a los enterramientos del presbiterio durante los trabajos de rehabilitación de la Catedral del Salvador.

Recapitulamos que según ratifica todavía a día de hoy el director del equipo de arqueólogos a cargo de las excavaciones de la Seo de 1994 José Antonio Hernández Vera, las tres alhajas objeto del presente trabajo se encontraron sobre el cuerpo del arzobispo, hijo natural de Fernando II de Aragón. No albergamos ninguna duda de que los discos góticos y el báculo pertenecieron a don Alonso; no obstante, cabría plantear si en el siglo XVIII, cuando se removieron las tumbas del presbiterio en la catedral del Salvador pudo manipularse el pectoral, habiendo pertenecido en origen al personaje de alto rango que se enterró en un primer momento en la fosa que hoy se identifica como de don Alonso. En cualquier caso el pectoral, como perteneciente al hijo de Fernando el Católico ha sido fondo de distintas exposiciones temporales.

De cualquier modo, estas alhajas son exponentes de la internacionalidad de las manifestaciones plásticas hispánicas, así como de la influencia del mundo italiano en el Reino de Aragón: el pectoral-relicario zaragozano, junto a la alhaja astorgana, son de las pocas joyas conservadas en el territorio hispánico de manufactura románica. Ambas piezas presentan conexiones con alhajas milanesas y estrechos paralelismos con cosmopolitas manifestaciones de las artes suntuarias europeas. Los discos esmaltados muestran los esbeltos cánones del gótico internacional, recreados según los preceptos técnicos de la escuela francesa; y por último, el báculo, aunque tipológicamente todavía responde a formas goticistas, presenta una crestería recortada que a modo de hojas de roble, anuncia la reinterpretación de los motivos decorativos clásicos como premisa fundamental de las tendencias renacientes.

\section{BIBLIOGRAFÍA}

Albersmeier, Sabine de (2005): Bedazzled, 5000 years of jewelry, Baltimore: The Walters Art Museum.

Ansón Navarro, Arturo (1991): "Colecciones de retratos de los obispos y arzobispos de Zaragoza hasta el siglo XVIII inclusive". En: El espejo de nuestra historia. La diócesis de Zaragoza a través de los siglos, Zaragoza: Ayuntamiento y Arzobispado de Zaragoza, pp. 145-148.

Arbeteta Mira, Letizia (1995): "Encolpión”. En: Jocalias para un aniversario, cat.exp., Zaragoza: Caja de Ahorros de la Inmaculada, pp. 188-195.

Bernis, Carmen (1962): Indumentaria española en tiempos de Carlos V, Madrid: CSIC.

Bernis, Carmen (1979): Trajes y Modas en la España de los Reyes Católicos, Vol. II, Los hombres, Madrid: CSIC.

Coordinación “Aragón, Reino y Corona" (C.A.R.C.) (2000): "Disco con esmalte”. En: Aragón, Reino y Corona (cat. exp.). Zaragoza: Ministerio de Educación y Cultura y Ayuntamiento de Madrid, p. 445, n. ${ }^{\circ}$ 271-272.

\footnotetext{
28 Se encontró fragmentado en cinco partes que se limpiaron y consolidaron en 1998: Blanco Ruano, Presupuesto para la restauración de un báculo procedente de los enterramientos del presbiterio de la catedral del Salvador de Zaragoza, inédito, 1998. Tres años después se hizo un alma nueva en metacrilato, que se fijó mediante espigas al nuevo soporte, aprovechando los resortes originales y posibilitando de este modo la exhibición de la pieza: Trácer, Restauración y Conservación S. L. (Madrid), Memoria final de restauración-conservación del báculo de don Alonso de Aragón, inédito, 2001. Ambos informes se conservan en el Servicio de Conservación y Restauración del Patrimonio Cultural de la Dirección General de Cultura y Patrimonio del Gobierno de Aragón (expedientes 46/98, signaturas 3796; 47/98, signaturas 3797 /29172; 20/97, signaturas 3794/29164). Además, la pieza se expuso en: Coordinación “Aragón, Reino y Corona" (C.A.R.C.), cat. exp. 2000: 446, n. ${ }^{\circ} 273$.
} 
Coordinación “Aragón, Reino y Corona” (C.A.R.C.) (2000): "Fragmento de báculo”. En: Aragón, Reino y Corona (cat. exp.) Zaragoza: Ministerio de Educación y Cultura y Ayuntamiento de Madrid, p. 446, n. ${ }^{\circ} 273$.

Criado Mainar, Jesús / Ibáñez Fernández, Javier (2007): “Alonso de Aragón, Isabel la Católica, Enrique Egas y la primera ampliación de la catedral de Zaragoza (1490-1522)". En: Ribot García, Luis Antonio / Valdeón Baruque, Julio / Maza Zorrilla, Elena (coords.) (2004): Isabel la Católica y su época: actas del congreso internacional, ValladolidBarcelona-Granada. Volumen II, Valladolid: Universidad de Valladolid, pp. 1421-1444.

Criado Mainar, Jesús (2014): "Los bustos relicarios femeninos en Aragón 1406-1567”. En: García Herrero, María del Carmen / Pérez Galán, Cristina (coords.), Mujeres de la Edad Media: actividades políticas, socioeconómicas y culturales, Zaragoza: Institución Fernando el Católico, p. 344.

De Arfe y Villafañe, J. (1572): Quilatador de la plata, oro y piedras. Madrid: Ministerio de Educación y Ciencia, edición facsímil, 1976, f.62v.

Evans, Joan (1970): A history of Jewellery 1100-1870. Nueva York: Dover Publications.

Galindo Pérez, Silvia (coord.) (2010): Aragón, Patrimonio Cultural Restaurado 1984/2009, Bienes Restaurados por la Dirección General de Patrimonio Cultural del Gobierno de Aragón. Bienes Muebles, Tomo 2, Zaragoza: Gobierno de Aragón.

Hernández Vera, José Antonio / Bienes Calvo, Juan José / Casasús Alcaine, José Ignacio (1997): “Excavaciones en la Seo del Salvador. Zaragoza”. En: Royo Guillén, José Ignacio (coord.): Arqueología Aragonesa 1994. Zaragoza: Departamento de Educación y Cultura.

Ibáñez Fernández, Javier (2000): "Precisiones sobre la política artística de don Alonso de Aragón, arzobispo de Zaragoza (1478-1520)". Boletín del Museo Camón Aznar, n. . 80, Zaragoza, espec. pp. 293-297.

Jorge Aragoneses, Manuel (1960-1961): "El broche románico de Santo Toribio de Liébana y su probable origen milanés". Anales de la Universidad de Murcia, Vol. 19, n. ${ }^{\circ}$ 1, Murcia, pp. 31-43.

Lozano López, Juan Carlos (2001-2003): "Las galerías de retratos episcopales en las Diócesis aragonesas". En: Aragonia Sacra, n. ${ }^{\circ}$ 16-17, Zaragoza, pp. 303-318, espec. pp. 312-315.

Morrison, Elizabeth (2003): "Master of the Soane Hours and another artist". En: Kren, Thomas; Mckendrick, Scot (eds.) (2003), Illuminating the Renaissance: the triumph of flemish manuscript painting in Europe, Los Ángeles: Getty Publications, p. 444 y ss.

Morte García, Carmen (1998): "Los arzobispos de la Casa Real: don Alonso, don Juan y don Hernando de Aragón (14781575)". En: VV.AA., La Seo de Zaragoza, Zaragoza, 1998, pp.175-247.

Morte García, Carmen (2000): "Patrocinio artístico de los reyes y de la nobleza en Aragón a finales del gótico y durante el Renacimiento". En: Actes de I, II, y III, col.loquis sobre art i cultura a l'època del Renaixement a la Corona d'Aragó (1996-1999): Tortosa: Ajuntament de Tortosa, espec. pp.147-155.

Naya Franco, Carolina (2015): “Cruz pectoral (encolpión) del arzobispo don Alonso de Aragón (1470-1520)”. En: Morte García, Camen / Sesma Muñoz, José Ángel (Com.): Fernando II de Aragón, el rey que imaginó España y la abrió a Europa / Zaragoza: Diputación General de Aragón, pp.192-193.

Naya Franco, Carolina (2015): "Discos esmaltados del arzobispo don Alonso de Aragón (1470-1520)". En: Morte García, Carmen / Sesma Muñoz, José Ángel (com.) (2015): Fernando II de Aragón, el rey que imaginó España y la abrió a Europa, Zaragoza: Diputación General de Aragón, pp. 194-195.

Naya Franco, Carolina (2017): Joyas y alhajas del Altoaragón: esmaltes y piedras preciosas de ajuares y tesoros históricos, Huesca: Diputación de Huesca, en prensa.

Robinson, James (2011): Finer than gold, Saints and relics in the Middle Ages, Londres: British Museum.

Torra de Arana, Eduardo (2000): "Encolpión de don Alonso de Aragón”. En: Aragón, Reino y Corona, cat.exp. Zaragoza: Ministerio de Educación y Cultura y Ayuntamiento de Madrid, n. ${ }^{\circ} 270$, p. 444.

Ubieto Arteta, Agustín (1957): "Notas sobre el obispo Esteban (1099-1130)". En Argensola, n. ${ }^{0} 29$, Huesca, p. 60.

Velardo Graña, Bernardo (2000): "Broche románico". En: Encrucijadas. Las edades del hombre: Catedral de Astorga, (cat.exp.), León, pp. 280-281.

Wagner de Kertesz (1947): Historia universal de las joyas a través del arte y la cultura. Buenos Aires: Ediciones Centurión.

Fecha de recepción: 13-IV-2016

Fecha de aceptación: 7-IX-2016 